\title{
Histiocytic hyperplasia with hemophagocytosis and acute alveolar damage in COVID-19 infection
}

\author{
Laura Prieto-Pérez ${ }^{1,2}$ • José Fortes ${ }^{1} \cdot$ Carlos Soto $^{1} \cdot$ Ánxela Vidal-González ${ }^{1} \cdot$ Marina Alonso-Riaño ${ }^{1}$ \\ Miguel Lafarga ${ }^{1}$ - María José Cortti ${ }^{1}$ - Alberto Lazaro-Garcia ${ }^{1}$ - Ramón Pérez-Tanoira ${ }^{1} \cdot$ Álvaro Trascasa $^{1}$. \\ Anabel Antonio ${ }^{1}$ - Raúl Córdoba ${ }^{1}$ - Socorro María Rodríguez-Pinilla ${ }^{1}$. Oderay Cedeño ${ }^{1} \cdot$ Germán Peces-Barba $^{1}$. \\ Itziar Fernández-Ormaechea ${ }^{1}$ María José Díez Medrano ${ }^{1}$ Marta López de Las Heras ${ }^{1} \cdot$ Alfonso Cabello $^{1}$. \\ Elizabet Petkova ${ }^{1} \cdot$ Beatriz Álvarez $^{1} \cdot$ Irene Carrillo $^{1} \cdot$ Andrés M. Silva $^{1} \cdot$ Marina Castellanos $^{1} \cdot$ Silvia Calpena $^{1}$. \\ Marcela Valverde-Monge ${ }^{1}$ - Diana Fresneda ${ }^{1} \cdot$ Rafael Rubio-Martín $^{1} \cdot$ Ignacio Cornejo ${ }^{1}$ • \\ Laura Astilleros Blanco de Cordova ${ }^{1} \cdot$ Soraya de la Fuente ${ }^{1} \cdot$ Sheila Recuero ${ }^{1} \cdot$ Miguel Górgolas $^{1} \cdot$ Miguel A. Piris $^{1}$
}

Received: 2 June 2020 / Revised: 16 June 2020 / Accepted: 16 June 2020 / Published online: 3 July 2020

(c) The Author(s), under exclusive licence to United States \& Canadian Academy of Pathology 2020

\begin{abstract}
The spectrum of COVID-19 infection includes acute respiratory distress syndrome (ARDS) and macrophage activation syndrome (MAS), although the histological basis for these disorders has not been thoroughly explored. Post-mortem pulmonary and bone marrow biopsies were performed in 33 patients. Samples were studied with a combination of morphological and immunohistochemical techniques. Bone marrow studies were also performed in three living patients. Bone marrow post-mortem studies showed striking lesions of histiocytic hyperplasia with hemophagocytosis (HHH) in most (16/17) cases. This was also observed in three alive patients, where it mimicked the changes observed in hemophagocytic histiocytosis. Pulmonary changes included a combination of diffuse alveolar damage with fibrinous microthrombi predominantly involving small vessels, in particular the alveolar capillary. These findings were associated with the analytical and clinical symptoms, which helps us understand the respiratory insufficiency and reveal the histological substrate for the macrophage activation syndrome-like exhibited by these patients. Our results confirm that COVID-19 infection triggers a systemic immune-inflammatory disease and allow specific therapies to be proposed.
\end{abstract}

\section{Background}

The full spectrum of COVID-19 infection ranges from asymptomatic disease, through mild respiratory tract illness, to severe pneumonia, acute respiratory distress syndrome (ARDS), multiorgan failure, and death. The virus induces

These authors contributed equally: Laura Prieto-Pérez, José Fortes, Miguel Górgolas and Miguel A. Piris

Laura Prieto-Pérez

lprietope@fjd.es

1 Servicio de Medicina Interna, UCI, Hematología, Anatomía Patológica, Fundación Jiménez Díaz, Ciberonc, Madrid, Spain

2 Present address: División de Enfermedades Infecciosas, Servicio de Medicina Interna, Hospital Universitario Fundación Jiménez Díaz, Madrid 28040, Spain the release of inflammatory cytokines, and it is their disruption of the immune response that can lead to multiorgan dysfunction and ARDS [1]. Growing evidence suggests that a subgroup of patients with severe disease might experience deregulated systemic inflammation in conjunction with cytokine storm syndrome, leading to fatality $[1,2]$.

There is an increasing interest in describing the histopathology of the organs involved in COVID-19 infection, through the study of samples obtained by means of core needle biopsies or full necropsies. Extending our knowledge will allow a better understanding of the disease and the development of new therapeutic targets.

The pulmonary pathology of the SARS infection has been thoroughly described [3-6]. It is known to comprise a combination of diffuse alveolar damage with airspace edema, bronchiolar fibrin, type II pneumocyte hyperplasia, squamous metaplasia, multinucleated giant cells, and occasional acute bronchopneumonia. Hyaline membranes were also identified in the acute phase of diffuse alveolar 
damage (DAD) $[3,4]$. The pulmonary pathology has also been described in isolated cases and a short series of COVID-19-infected patients [5-11], where similar changes to those seen in SARS have been found.

In the few studies of autopsies performed in patients who died from SARS or MERS infection, the bone marrow showed no significant changes $[4,12]$. However, in spite of the abundance of analytical data suggesting that bone marrow may play a significant role in the pathogenesis of the disease, we are not aware of any descriptions of bone marrow histology in the context of COVID-19 infection.

In this paper, we describe some histological findings from post-mortem lung and bone marrow samples of patients who had died from COVID-19 infection, and we discuss how these illuminate our understanding of this disorder. Furthermore, clinical and histological data from living COVID-19 patients who met the criteria for a diagnosis of hemophagocytic syndrome are also described and compared with the findings from deceased patients.

\section{Methods}

\section{Study design}

Post-mortem biopsies of patients who died with a diagnosis of COVID-19 were performed between March 18th and April 17th $2020(n=33)$. Bone marrow and lung tissues were selected for study with the expectation that understanding these patients' pathology would help explain their clinical features.

The post-mortem interval between death and biopsy was less than 3 hours in every case. During this time, informed consent was obtained from each patient's family. This study was approved by the local institutional review board and the Ethics Committee of the IIS-University Hospital Fundación Jiménez Díaz of Madrid, Spain.

22 lung and 17 bone marrow biopsy samples were obtained; the 16 patients with both lung and bone marrow samples available were studied.

Additionally, routine bone marrow biopsies were performed in three patients, two of whom had a previous clinical history of hematological disorders.

\section{Biopsy technique}

Lung samples were taken in random areas by percutaneous puncture using a 33-mm 14-gauge automatic biopsy gun, and were preserved in formaldehyde for a $72 \mathrm{~h}$ period before they were studied. All bone marrow biopsies were taken from the posterior-superior iliac spine, fixed and processed as routine bone marrow biopsies using the reagents Myelodec ${ }^{\circledR}$ (Bio-Optica).
Other tissues obtained in the postmortem procedure were not included in this study.

\section{Additional procedures}

In every case, SARS-CoV-2 infection was confirmed by RT-PCR of material collected on nasopharyngeal swabs (Viasure ${ }^{\circledR}$ SARS-CoV-2 Real-Time PCR detection kit).

Tissues were examined under a light microscope in accordance with routine hematoxylin-eosin and immunohistochemistry (IHC) staining protocols. The COVID19 IHC test was done using the antibody GTX632604 (Genetex), which detects both the SARS-CoV spike and the SARS-CoV-2 spike proteins (S2 subunit). CD163 (CM353A) antibody was obtained from Biocare, and Glycophorin A (M0819) antibody was obtained from DAKO.

Continuous variables are expressed as the median and interquartile range (IQR); categorical variables are summarized as proportions. Statistical analysis was performed with SPSS v20.0 (IBM ${ }^{\circledR}$ Corp., Armonk, NY, USA).

\section{Results}

\section{Clinical characteristics}

\section{Deceased patients}

The median age of the 33 patients was 79 years (53-98 years); $36 \%$ were women. Most of the study cohort had chronic underlying health conditions, with hypertension (45\%), diabetes mellitus (30\%), pulmonary disease (27\%), and cardiac disease (18\%) being the most common. Onset of symptoms occurred from 1 to 15 days before admission. The mean hospitalization time before death was 5 days (IQR 1.5-11) with the longest hospital stay of 27 days. Three patients died within $24 \mathrm{~h}$ of admission, nine patients died after treatment in the ICU with mechanical ventilation requirement, 16 patients received standard treatment during hospitalization, and palliative care was prioritized for five patients. The results of laboratory tests were remarkable for the elevated levels of D-dimer (median, $3114 \mu \mathrm{g} / \mathrm{L}$ [range, 1176-5090 $\mu \mathrm{g} / \mathrm{L}$ ]), ferritin (median, $1469 \mu \mathrm{g} / \mathrm{L}$ [range 499-1842 $\mu \mathrm{g} / \mathrm{L}$ ]), lymphopenia (median, $700 \mu \mathrm{g} / \mathrm{L}$ [range, $400-1100 \mu \mathrm{g} / \mathrm{L}$ ]) and IL-6 levels (median, $40.6 \mu \mathrm{g} / \mathrm{L}$ [range, 16.7-94.9 $\mu \mathrm{g} / \mathrm{L}$ ]). Clinical features, symptoms, radiological, laboratory findings and medical treatment are shown in Table 1 .

\section{Hemophagocytic lymphohistiocytosis in alive patients}

Due to a strong clinical suspicion of hemophagocytic lymphohistiocytosis (HLH), bone marrow was biopsied in 
Table 1 Demographic and clinical characteristics at the time of death $(N=33$ cases $)$.

\begin{tabular}{|c|c|c|c|}
\hline & Median & IQR & Range \\
\hline \multicolumn{4}{|l|}{ Characteristic } \\
\hline Age (years) & 79 & $66-87$ & 53-98 \\
\hline Sex & $\begin{array}{l}\text { Female: } \\
12(36 \%)\end{array}$ & $\begin{array}{l}\text { Male: } \\
21(64 \%)\end{array}$ & \\
\hline Onset of symptoms (days before admission) & 5 & $2-7$ & $1-15$ \\
\hline Length of hospital stay (days) & 5 & $(1.5-11)$ & \\
\hline \multicolumn{4}{|l|}{ Initial clinical presentation } \\
\hline Fever & $23(70 \%)$ & & \\
\hline Dyspnea & $17(57 \%)$ & & \\
\hline \multirow[t]{2}{*}{ Cough } & $13(39 \%)$ & & \\
\hline & Median & IQR & Range \\
\hline \multicolumn{4}{|l|}{ Laboratory results } \\
\hline $\mathrm{Hb}(13-17 \mathrm{~g} / \mathrm{L})$ & 12.1 & $11-14.2$ & $8.10-17.80$ \\
\hline Platelets $\left(150-450 \times 10^{3} \mu \mathrm{l}\right)$ & $223 \times 10^{3}$ & $(145-289) \times 10^{3}$ & $(28-539) \times 10^{3}$ \\
\hline Lymphocyte count (1200-5000 abs) & 700 & $400-1100$ & $100-1800$ \\
\hline Creatinine $(0.67-1.17 \mathrm{mg} / \mathrm{dL})$ & 1.3 & $0.8-1.7$ & $0.4-5.10$ \\
\hline Ferritin $(30-400 \mathrm{ng} / \mathrm{mL})$ & 1469 & $499-1842$ & $96-9404$ \\
\hline 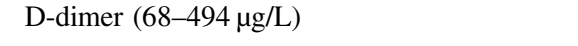 & 3114 & $1176-5090$ & $522-64,533$ \\
\hline C-reactive protein $(<0.5 \mathrm{mg} / \mathrm{dL})$ & 10.9 & $4.55-28.2$ & $0.50-40.1$ \\
\hline IL-6 (<7 pg/mL) & 40.6 & $16.7-94.9$ & $6.70-241.4$ \\
\hline \multicolumn{4}{|l|}{ Radiological findings } \\
\hline Interstitial infiltrates with centrilobular nodules & 13 & & \\
\hline Ground-glass opacities & 6 & & \\
\hline Ill-defined consolidation & 14 & & \\
\hline \multicolumn{4}{|l|}{ Treatment } \\
\hline PB-ST & 26 & & \\
\hline Tocilizumab & 4 & & \\
\hline Palliative supportive care & 5 & & \\
\hline
\end{tabular}

PB-ST protocol-based standard-therapy: hydroxychloroquine, LPV/r, methylprednisolone, low-weight molecular heparin and antibiotic coverage (levofloxacin, doxycycline or azithromycin). IQR interquartile range. three alive patients. The clinical features of living patients with confirmed HLH are shown in Table 2.

\section{Bone marrow histology}

There was a relative increase in overall cellularity in bone marrow in all cases; the most conspicuous finding was the presence of scattered macrophages that engulfed erythrocytes and erythroblasts (Fig. 1). Although the relative proportions of these cells differed from case to case, they were present in 16/17 cases. CD163 staining and double CD163/Glycophorin (a marker of red cells) highlighted this phenomenon (Fig. 1). Macrophages containing hemosiderin were also frequently found. Occasional multinucleate histiocytes were also noted. Additionally, most samples contained aggregates of CD8+ interstitial lymphocytes and occasionally interstitial lymphoid primary follicles. Plasma cells were present in proportions from 1 to $4 \%$.
Myeloid cells were more prevalent in every case, with a ratio of myeloid/erythroid (M:E) cells ranging from 4 to 8 . Within the myeloid lineage, most cases exhibited a relatively higher proportion of myelocytes + metamyelocytes, with a relatively lower proportion of mature neutrophils.

Other bone marrow findings included the frequent presence of clusters of megakaryocytes. No granulomas were noted in any of the cases.

The results are summarized in Table 3 .

Additionally, in the three living COVID-19 infected patients who fulfilled the criteria for a secondary histiocytic lymphohistiocytosis (sHLH) diagnosis, the bone marrow showed similar findings, and with notable erythrophagocytic phenomena.

\section{Pulmonary histology}

Of the 22 lung samples obtained, two were not eligible for appropriate histopathological analysis. 
Table 2 Demographic and clinical features of living patients with confirmed HLH $(n=3$ cases).

Fig. 1 Bone marrow histology. Bone marrow cores showing increased cellularity with presence of CD 163-positive macrophages and striking hemophagocytosis, as disclosed by double-staining with CD163 and glycophorin.

\begin{tabular}{|c|c|c|c|c|}
\hline & $\begin{array}{l}\text { Age } \\
\text { (years) }\end{array}$ & Gender & Medical history & HLH criteria fulfilled \\
\hline Patient 1 & 60 & M & $\begin{array}{l}\text { Acute myeloid leukemia M5b, } 2019 \\
\text { (complete remission) }\end{array}$ & $\begin{array}{l}\text { - Fever } \\
\text { - Hb } 7.4 \mathrm{~g} / \mathrm{dL} \text {, platelets } 54,000 / \mathrm{mm}^{3} \\
\text { - Ferritin } 7790 \mathrm{ng} / \mathrm{mL} \\
\text { - CD25s: } 2932 \mathrm{UI} / \mathrm{mL} \\
\text { - Hemophagocytosis in } \\
\text { bone marrow }\end{array}$ \\
\hline Patient 2 & 70 & $\mathrm{~F}$ & $\begin{array}{l}\text { Atrial fibrillation, asthma, colorectal } \\
\text { cancer (complete remission) chronic } \\
\text { kidney disease }\end{array}$ & $\begin{array}{l}\text { - Fever } \\
\text { - Hb } 7.1 \mathrm{~g} / \mathrm{dL} \text {, platelets } 23,000 / \mathrm{mm}^{3} \\
\text { - Ferritin } 16,248 \mathrm{ng} / \mathrm{mL} \\
\text { - sCD25: } 1165 \mathrm{UI} / \mathrm{mL} \\
\text { - Hemophagocytosis in } \\
\text { bone marrow }\end{array}$ \\
\hline Patient 3 & 45 & $\mathrm{~F}$ & $\begin{array}{l}\text { Follicular lymphoma (complete } \\
\text { remission) }\end{array}$ & $\begin{array}{l}\text { - Fever } \\
\text { - Ferritin } 2288 \mathrm{ng} / \mathrm{mL} \\
\text { - Splenomegaly } \\
\text { - sCD25: } 1512 \mathrm{UI} / \mathrm{mL} \\
\text { - Hemophagocytosis in } \\
\text { bone marrow }\end{array}$ \\
\hline
\end{tabular}

HLH Hemophagocytic lymphohistiocytosis.
Table 3 Main findings in bone marrow biopsies.

\begin{tabular}{ll}
\hline Finding & $\begin{array}{l}\text { Number of cases } \\
(N=17)\end{array}$ \\
\hline Hemophagocytosis & 16 \\
Multinucleate giant cells & 1, scattered \\
Increased proportion of myelocytes + & 12 \\
metamyelocytes & 13 \\
T-cell lymphocytosis (CD8) & 9 \\
B-cell lymphocytosis & \\
\hline
\end{tabular}

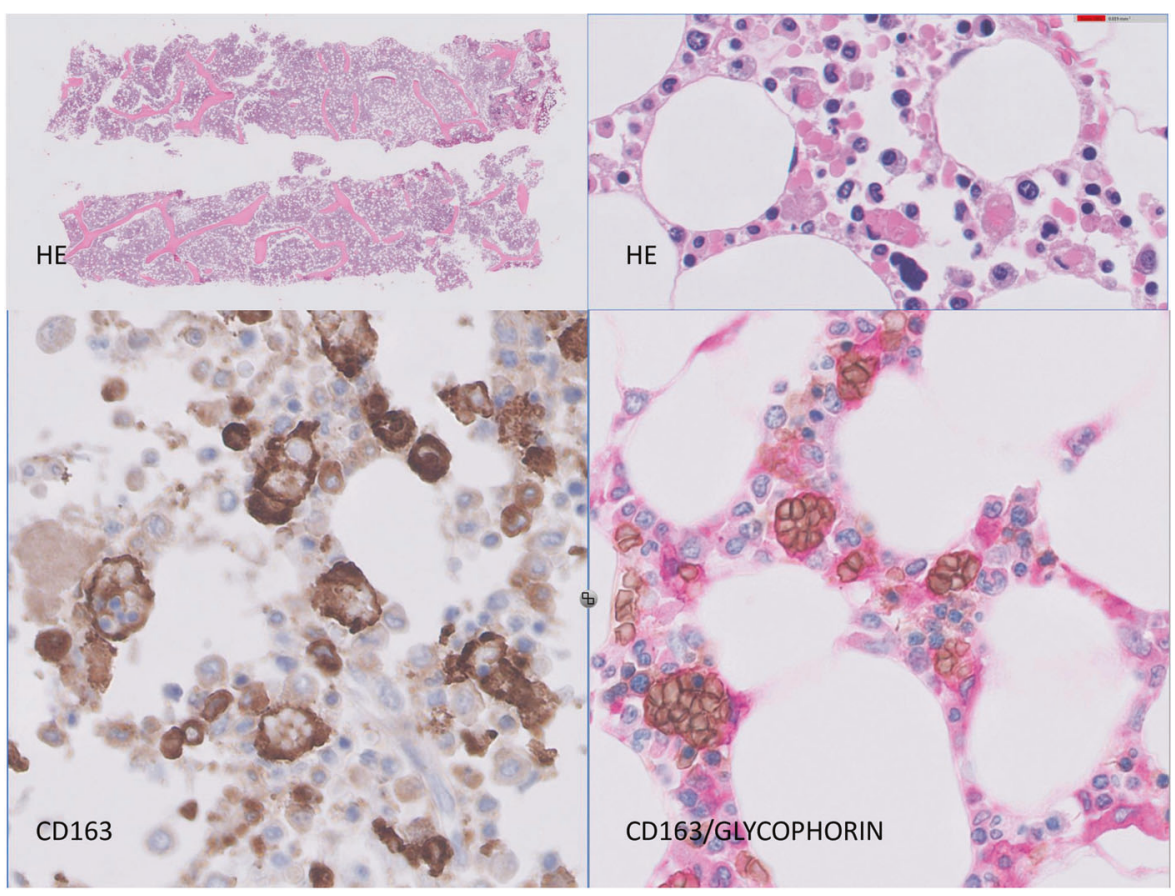

The most widespread findings were lesions of acute DAD, with the frequent formation of hyaline membranes, associated with fibrin and intra-alveolar cell detritus; focal signs of exudate organization were present in 14 of the 20 valid samples, and the other two samples showed a predominant organizing pattern. Squamous metaplasia was identified in three samples and there were foci of bronchopneumonia in four others. DAD lesions of similar intensity were present in patients inside and outside the ICU (Figs. 2 and 3). 
Fig. 2 Pulmonary histology.

Histological changes of acute diffuse alveolar damage, with the formation of hyaline membranes, pneumocyte II hyperplasia, associated with fibrin and intra-alveolar cell detritus, with scattered thrombi.

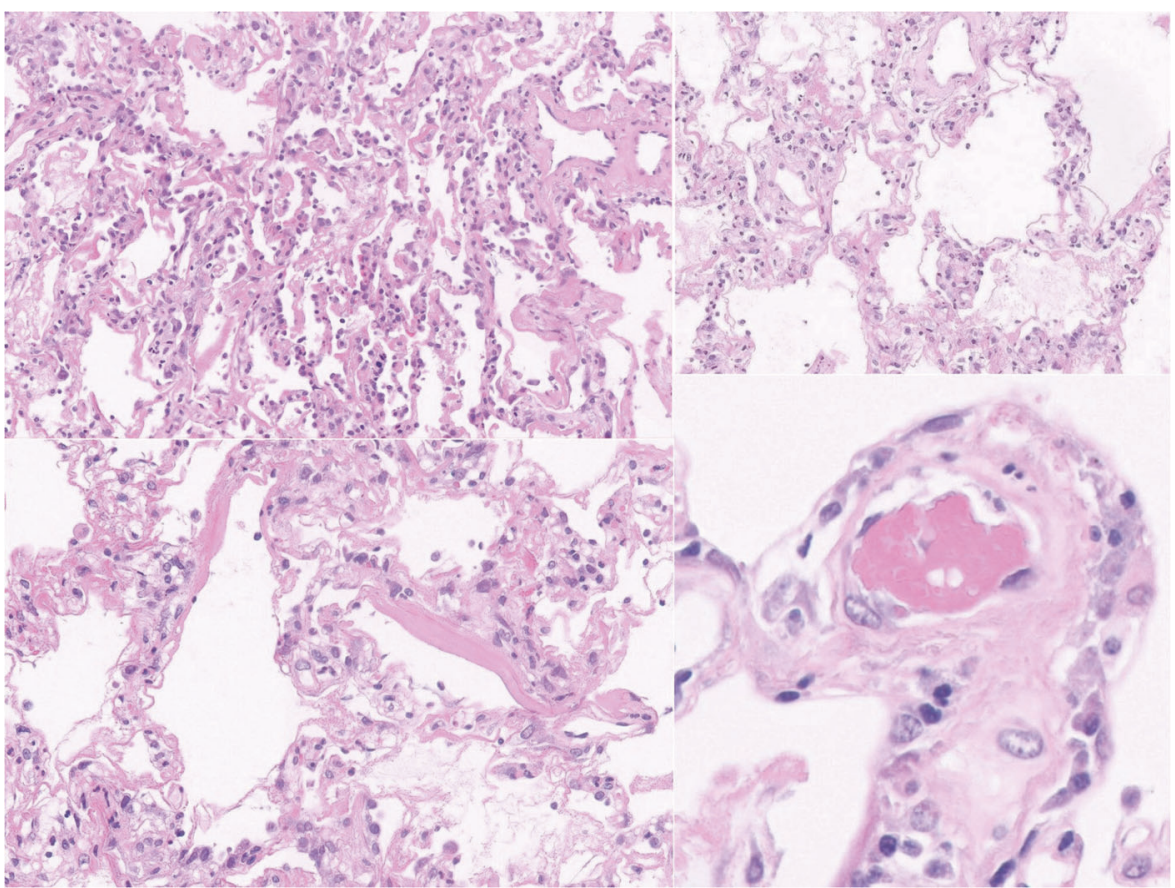

Fig. 3 Thrombosis of the alveolar microcapillary. Shown by morphological techniques (HE), Masson staining and IHC for FVIII recognition of platelets and endothelial cells.

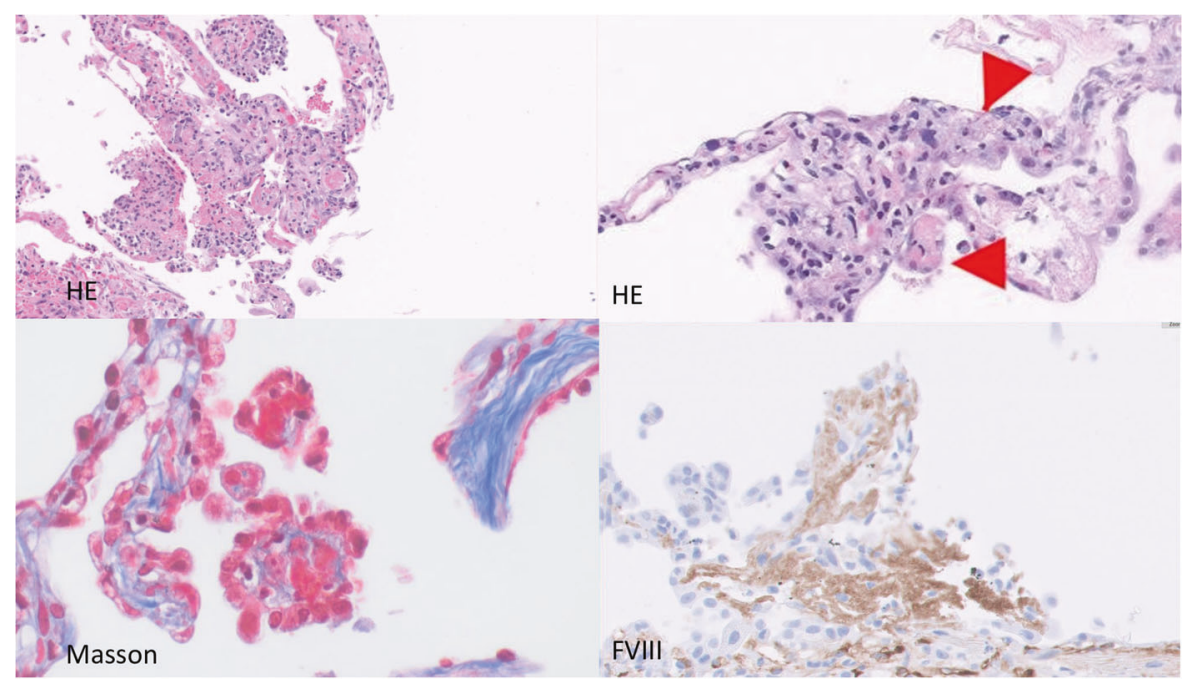

Numerous fibrinous microthrombi were identified in 12 patients, where they predominantly affected small vessels, in particular the alveolar capillary, but showed no signs of vasculitis (Fig. 3).

IHC studies of COVID-19 were performed in one case, revealing scattered COVID-19-positive pneumocytes (Fig. 4).

A lymphohistiocytic inflammatory infiltrate was patchily distributed in all cases. IHC studies revealed the presence of numerous CD163-positive macrophages, which were distributed in both interstitial and alveolar spaces. Occasionally, these CD163+ macrophages were found to contain engulfed neutrophils. Scattered CD8+ cells were also identified; no relationship between the number of
CD8 cells and the severity of alveolar damage was observed (Figs. 2 and 4).

The main pulmonary findings are shown in Table 4.

TH17-cells and T-reg cells were not identified in pulmonary biopsies after ROR Gamma and FOXP3 staining. Negligible or minimal frequencies of B cells were noted in pulmonary tissue after CD20 and CD79 staining.

In two cases, an electron microscopy study was performed on the pulmonary samples. Findings confirmed the presence of microthrombosis and allowed features of endothelial and pneumocyte II damage to be identified, together with numerous images consistent with viral particles of morphology and size consistent with coronaviruses (Fig. 5). 


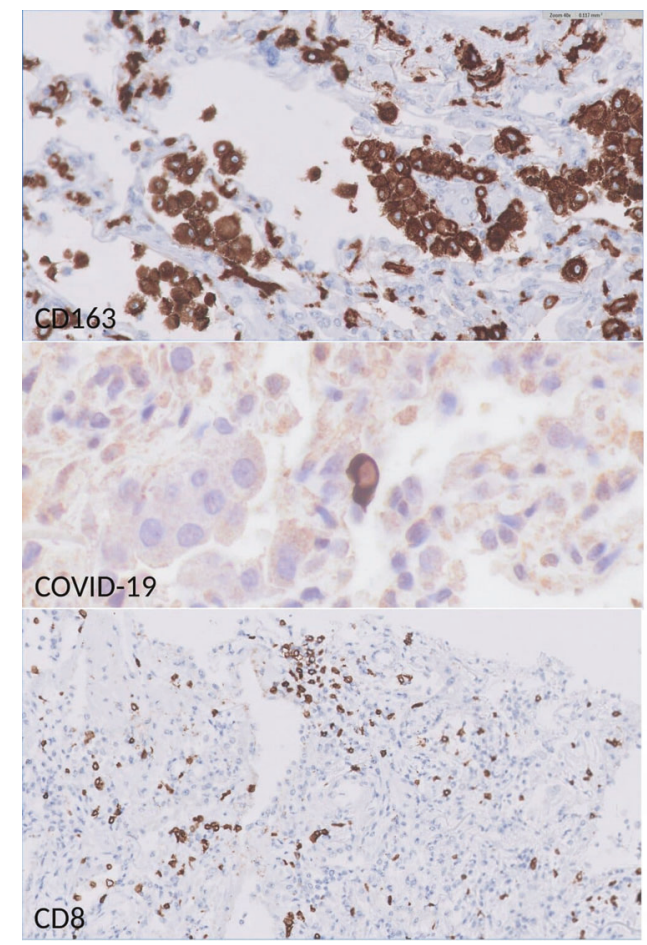

Fig. 4 IHC stainings in pulmonary samples: high frequency of CD163-positive macrophages. Presence of CD8-positive interstitial lymphocytosis. Scattered pneumocytes were positive for COVID-19 immunostaining.

Table 4 Frequency of the main pulmonary findings.

\begin{tabular}{ll}
\hline Finding & Number of cases $(N=20)$ \\
\hline Diffuse alveolar damage & 20 \\
Hyaline membrane & 20 \\
Capillary thrombi & 12 \\
CD163+ macrophages & 20, diffuse, interstitial and alveolar \\
CD8 lymphocytes & 20, scattered pattern \\
\hline
\end{tabular}

\section{Discussion}

Histopathological and IHC studies of COVID-2 patients have begun to reveal unexpected changes that are leading to a better understanding of the peculiar clinical features of this disorder. We examined biopsies of the lung and bone marrow, obtained immediately after the patients died, which allowed us to carry out a detailed morphological and immunohistochemical study with freshly fixed tissue. Lung and bone marrow were chosen for examination on account of the frequency and clinical relevance of their involvement in COVID-19.

Pulmonary changes show lesions of diffuse alveolar damage (DAD), which basically mimic those described in acute respiratory distress syndrome (ARDS), and have already been described in COVID-19 autopsy studies [5-7, 9-11].
DAD can be triggered by many pathogenic stimuli, including viruses. Our findings coincide with those of Franks and Hwang et al., who studied patients who had died from SARS infection during the outbreak in 2003 [3, 13].

Special attention was paid in the examination of pulmonary samples to assess whether changes in cell damage were present in both type II-pneumocytes and endothelial cells. EM studies seem to reveal severe cellular damage in both cell types, a finding that is highly consistent with the presence of viral particles in both cell types.

Although no features of pulmonary ischemia were identified, a high frequency of fibrinous microthrombi was present in $12 / 20(60 \%)$ of the samples, consistent with the previously published descriptions [5-7, 9-11]. An increased level of D-dimer was detected in most of the 33 deceased patients in the last laboratory test before their death, with a median value of $3114 \mu \mathrm{g} / \mathrm{L}$ (range, $522-64,533 \mu \mathrm{g} / \mathrm{L}$ ), and in more than half of the patients the D-dimer value was above $3000 \mu \mathrm{g} / \mathrm{L}$. Coagulopathy in coronavirus infection is associated with a probability of mortality, with high levels of D-dimers being a particularly important marker [14]. As recently stated by Tang et al, anticoagulant therapy, mainly with LMWH, appears to be associated with better prognosis in severely affected COVID-19 patients who meet the sepsis-induced coagulopathy (SIC) criteria, or who have a markedly elevated level of D-dimer [15]. Both characteristics are used to determine the risk of a thrombotic event in coronavirus infection [16]. However, thrombocytopenia, one of the SIC criteria, was present in only one patient, who had a previous diagnosis of corticosteroid-dependent immune thrombocytopenia.

Bone marrow study results show findings consistent with the diagnosis of hemophagocytic histiocytosis $(\mathrm{HH})$ in the postmortem biopsies and in the studies performed on living patients. $\mathrm{HH}$ is a frequent finding associated with severe viral diseases, and represents the histological counterpart of the macrophage activation syndrome (MAS) that these patients suffer. MAS, which is also known as secondary histiocytic lymphohistiocytosis (sHLH), is an underrecognized syndrome characterized by the overactivation of cytotoxic $\mathrm{T}$ cells with hemophagocytosis by macrophages, and the massive release of inflammatory cytokines. For these reasons, it is classified among the cytokine storm syndromes. In addition to the primary form, most cases are associated and triggered by malignancies or a variety of infections (viral, bacteria, fungi or parasites) [17], occurring in $3.7-4.3 \%$ of sepsis cases [18].

A cytokine profile resembling sHLH is associated with COVID-19 disease severity, and characterized by increased interleukin (IL)-2, IL-7, granulocyte colony-stimulating factor, interferon- $\gamma$-inducible protein 10 , monocyte chemoattractant protein 1 , macrophage inflammatory protein $1-\alpha$, and tumor necrosis factor- $\alpha$ [2]. The similarities 


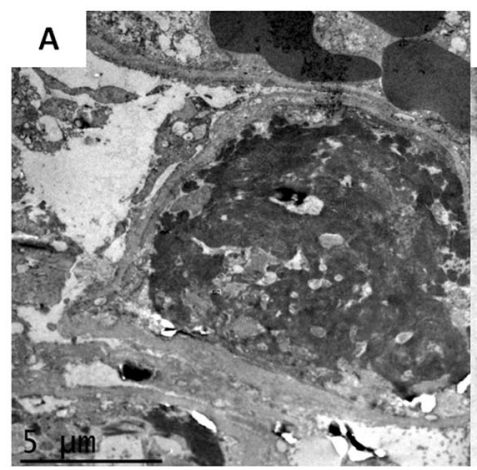

Fig. 5 Electron microscopy images of the pulmonary biopsies in two patients. a Case 20-262: Image of capillary thrombosis. Fibrin clot completely occludes the capillary light. b Case 20-262:

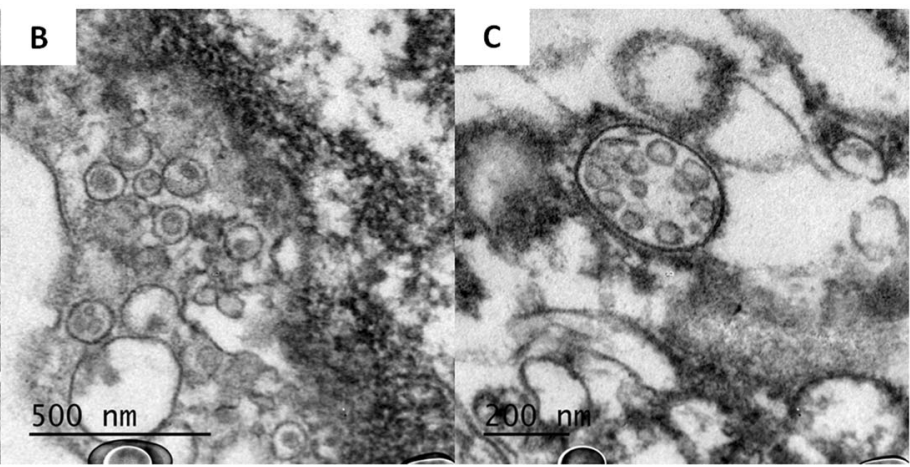

Cytoplasmic vesicles containing particles of size and morphology consistent with coronavirus c Case 20-263: Spherical coronavirus particles clustered within a membrane. between MAS and sHLH have already been pointed out, and the possibility that the stronger immune response seen in these patients may lead to COVID-19-related ARDS has also been raised $[2,19]$. Increased ferritin levels support this hypothesis, and are consistent with the findings in our study, in which we recorded a mean ferritin level of 1469 $\mathrm{ng} / \mathrm{mL}$ (range, $96-9404 \mathrm{ng} / \mathrm{mL}$ ).

A final diagnosis of HLH requires five of the eight HLH-2004 diagnostic criteria to be met [20]. The cases described here do not meet all the criteria required for a secondary HLH diagnosis [21], even though, according to the recurrent finding of erythrophagocytosis in bone marrow samples, we think they might represent a specific hemophagocytic disorder associated with COVID-19. Histiocytic hyperplasia with hemophagocytosis (HHH) has been described as a common finding in studies performed in autopsies of critically ill medical patients [22], but some of the cases denominated as such could easily fit within the HLH spectrum. In addition, we report a short series of three living patients with the same histological findings and who fulfilled the clinico-analytical criteria for a diagnosis of HLH. This finding could have some therapeutic implications, since it is known that HLH patients may respond to a combination of etoposide, dexamethasone and cyclosporine A [21,23].

It is still unclear whether vascular lesions, a frequent phenomenon in COVID-19 patients, is the consequence of direct endothelial infection by the virus or is secondary to the MAS/HLH, a severe disorder where, in addition to unremitting fever, cytopenias, and hyperferritinemia, pulmonary lesions of ARDS have been found in approximately $50 \%$ of patients [19]. Thus, the dominant feature of MAS/ sHLH is the overactivation of tissue macrophages, which releases a storm of cytokines that leads to rapidly progressing organ dysfunction in which pancytopenia, tissue hemophagocytosis, hepatobiliary dysfunction, disseminated intravascular coagulation (DIC) and dysfunction of the central nervous system predominate. In MAS, soluble CD163 is greatly augmented, reflecting the greater number of activated macrophages [18], as present in all examined tissues in this series.

Our findings confirm that human tissues affected by COVID-19 infection do indeed harbor a constellation of features consistent with the hypothesis that COVID-19 infection triggers a systemic immune-inflammatory disease. They support the proposition that the use of anti-cytokine therapy, inhibiting pro-inflammatory cytokines IL1 and IL6, is an effective therapeutic approach. It mitigates the hyperinflammation that may occur in conjunction with this virally induced ARDS, in which an autocrine loop of interleukin (IL)-1 $\beta$ over-secretion leads to a cytokine storm of IL-6, IL18, ferritin, and interferon-gamma [18, 19].

Acknowledgements We would first like to express our deepest gratitude to the patients and their families, who, in a time of grief, have contributed to our understanding of this disease. We are also grateful to the entire team of physicians and health personnel for their tireless, altruistic dedication, strength and effort during the current pandemic. We would like to acknowledge Ángeles Montero-Fernández, PhD from the Manchester University NHS Foundation Trust, and Miguel Lafarga $\mathrm{PhD}$, from Universidad de Cantabria-IDIVAL, for shedding light on the interpretation of the results. We thank Guido Rodríguez and Juan S. Verde from «Yo, Doctor» for the design and execution of the visual abstract. Finally, we are indebted to Laura Cereceda, for her valuable role as data manager.

Funding MA Piris received grants from the Instituto de Salud Carlos III, from the Ministerio de Economía, Industria y Competitividad [PIE15/0081 and PIE16/01294; SAF2013-47416-R, CIBERONCISCIII, ISCIII-MINECO-AES-FEDER (Plan Estatal I+D+I 2013-2016)], the Asociación Española Contra el Cáncer [AECC PROYE18054PIRI], and the Comunidad Autónoma de Madrid [CAM B2017/BMD-3778, PIC97/2017_FJD].

\section{Compliance with ethical standards}

Conflict of interest The authors declare that they have no conflict of interest. 
Publisher's note Springer Nature remains neutral with regard to jurisdictional claims in published maps and institutional affiliations.

\section{References}

1. Channappanavar R, Perlman S. Pathogenic human coronavirus infections: causes and consequences of cytokine storm and immunopathology. Semin Immunopathol. 2017;39:529-39.

2. Mehta P, McAuley DF, Brown M, Sanchez E, Tattersall RS, Manson JJ, et al. COVID-19: consider cytokine storm syndromes and immunosuppression. Lancet. 2020;395:1033-4.

3. Franks TJ, Chong PY, Chui P, Galvin JR, Lourens RM, Reid AH, et al. Lung pathology of severe acute respiratory syndrome (SARS): a study of 8 autopsy cases from Singapore. Hum Pathol. 2003;34:743-8.

4. Ding Y, Wang H, Shen H, Li Z, Geng J, Han H, et al. The clinical pathology of severe acute respiratory syndrome (SARS): a report from China. J Pathol. 2003;200:282-9.

5. Menter T, Haslbauer JD, Nienhold R, Savic S, Hopfer H, Deigendesch N, et al. Post-mortem examination of COVID19 patients reveals diffuse alveolar damage with severe capillary congestion and variegated findings of lungs and other organs suggesting vascular dysfunction. Histopathology. 2020. https://doi.org/10. 1111/his.14134.

6. Zhang H, Zhou P, Wei Y, Yue H, Wang Y, Hu M, et al. Histopathologic changes and SARS-CoV-2 immunostaining in the lung of a patient with COVID-19. Ann Intern Med. 2020;172:629-32.

7. Tian S, Hu W, Niu L, Liu H, Xu H, Xiao SY. Pulmonary pathology of early-phase 2019 novel coronavirus (COVID-19) pneumonia in two patients with lung cancer. J Thorac Oncol. 2020;15:700-4.

8. Xu X, Barth RF, Buja LM. A call to action: the need for autopsies to determine the full extent of organ involvement associated with COVID-19 infections. Chest. 2020. https://doi.org/10.1016/j. chest.2020.03.060.

9. Barton LM, Duval EJ, Stroberg E, Ghosh S, Mukhopadhyay S. COVID-19 autopsies, Oklahoma, USA. Am J Clin Pathol. 2020; 153:725-33.

10. Yao XH, Li TY, He ZC, Ping YF, Liu HW, Yu SC. et al. A pathological report of three COVID-19 cases by minimally invasive autopsies. Zhonghua Bing Li Xue Za Zhi. 2020;49:E009.

11. Xu Z, Shi L, Wang Y, Zhang J, Huang L, Zhang C, et al. Pathological findings of COVID-19 associated with acute respiratory distress syndrome. Lancet Respir Med. 2020;8:420-2.
12. Ng DL, Al Hosani F, Keating MK, Gerber SI, Jones TL, Metcalfe MG, et al. Clinicopathologic, immunohistochemical, and ultrastructural findings of a fatal case of Middle East respiratory syndrome coronavirus infection in the United Arab Emirates, April 2014. Am J Pathol. 2016;186:652-8.

13. Hwang DM, Chamberlain DW, Poutanen SM, Low DE, Asa SL, Butany J. Pulmonary pathology of severe acute respiratory syndrome in Toronto. Mod Pathol. 2005;18:1-10.

14. Tang N, Li D, Wang X, Sun Z. Abnormal coagulation parameters are associated with poor prognosis in patients with novel coronavirus pneumonia. J Thromb Haemost. 2020;18:844-7.

15. Tang N, Bai H, Chen X, Gong J, Li D, Sun Z. Anticoagulant treatment is associated with decreased mortality in severe coronavirus disease 2019 patients with coagulopathy. J Thromb Haemost. 2020;18:1094-9.

16. Thachil J. The versatile heparin in COVID-19. J Thromb Haemost. 2020;18:1020-2.

17. Ramos-Casals M, Brito-Zeron P, Lopez-Guillermo A, Khamashta MA, Bosch X. Adult haemophagocytic syndrome. Lancet. 2014; 383:1503-16.

18. Karakike E, Giamarellos-Bourboulis EJ. Macrophage activationlike syndrome: a distinct entity leading to early death in sepsis. Front Immunol. 2019;10:55.

19. McGonagle D, Sharif K, O'Regan A, Bridgewood C. The role of cytokines including interleukin-6 in COVID-19 induced pneumonia and macrophage activation syndrome-like disease. Autoimmun Rev. 2020;19:6. https://doi.org/10.1016/j.autrev.2020.102537.

20. Henter JI, Horne A, Arico M, Egeler RM, Filipovich AH, Imashuku S, et al. HLH-2004: diagnostic and therapeutic guidelines for hemophagocytic lymphohistiocytosis. Pediatr Blood Cancer. 2007;48:124-31.

21. La Rosee $\mathrm{P}$, Horne $\mathrm{A}$, Hines $\mathrm{M}$, von Bahr Greenwood $\mathrm{T}$, Machowicz R, Berliner N, et al. Recommendations for the management of hemophagocytic lymphohistiocytosis in adults. Blood. 2019; 133:2465-77.

22. Strauss R, Neureiter D, Westenburger B, Wehler M, Kirchner T, Hahn EG. Multifactorial risk analysis of bone marrow histiocytic hyperplasia with hemophagocytosis in critically ill medical patients-a postmortem clinicopathologic analysis. Crit Care Med. 2004;32:1316-21.

23. Bergsten E, Horne A, Arico M, Astigarraga I, Egeler RM, Filipovich $\mathrm{AH}$, et al. Confirmed efficacy of etoposide and dexamethasone in HLH treatment: long-term results of the cooperative HLH-2004 study. Blood. 2017;130:2728-38. 